\title{
Conduction aphasia following metrizamide myelography
}

\author{
DANIEL KASSICIEH, DO \\ MILES E. DRAKE, JR., MD \\ EDWIN C. SHUTTLEWORTH, MD \\ KOTTIL W. RAMMOHAN, MD
}

\begin{abstract}
Aphasia rarely has been reported after the use of metrizamide as contrast medium in myelography. In the present case of conduction aphasia

following metrizamide myelography, there was electroencephalographic evidence of generalized encephalopathy, a computed tomography scan revealing generalized metrizamide uptake, and no evidence of a lesion in the arcuate fasciculus. This case extends the range of neurologic complications to metrizamide studies for which clinicians must be alert. It supports recent clinical and pathologic suggestions that conduction aphasia may result from a number of disturbances involving the centers subserving language comprehension and speech production, including the generalized dysfunction of toxic-metabolic encephalopathy.
\end{abstract}

A variety of neurologic complications following myelography with metrizamide have been described. ${ }^{1-7}$ These have ranged from minor symptoms (headache, nausea, and vomiting) to serious side effects (aseptic meningitis and encephalopathy, as characterized by seizures, myoclonus, or alterations in sensorium. ${ }^{2-7}$ ) Aphasias are much rarer side effects of metrizamide myelography. ${ }^{8,9}$

The case of conduction aphasia following metrizamide myelography reported here is of interest not only as documentation of another potential adverse effect of this commonly used agent, but also because of the controversy that surrounds the pathophysiology of this type of aphasia. ${ }^{10-12}$ Although conduction aphasia generally is considered to represent a disconnection syndrome secondary to pathology in the arcuate fasciculus or subinsular pathway, autopsy studies usually have identified coexisting cortical, mostly posterior perisylvian, pathology. The occurrence of conduction aphasia in the setting of a toxic-metabolic encephalopathy following metrizamide use would favor the hypothesis that this type of language disturbance can be asso- ciated with disorders in the cortical perisylvian speech areas rather than exclusively as a result of dysfunction of the subcortical pathways, as has been thought traditionally.

\section{Report of case}

A 51-year-old, right-handed man was evaluated for progressive paraparesis, which had evolved over a fiveyear period. His past history was remarkable only for hypertension. Iophenydylate myelography performed five years earlier had been unremarkable.

The patients' general examination had normal findings, and neurologic examination showed intact cranial nerve and upper extremity function. Examination of the lower extremities demonstrated marked symmetric weakness in muscle groups, with symmetric hyperreflexia. Plantar stimulation produced extensor responses bilaterally. A sensory level could not be defined, but there was blunting of all sensory modalities below the knees on both sides. Because the patient complained of urinary urgency, bladder function also appeared to be affected. Speech and language functions were entirely normal.

Complete metrizamide myelography, using $6.75 \mathrm{~g}$ of contrast agent $(290 \mathrm{mg} / \mathrm{ml})$, was carried out. This revealed a central filling defect of the L3-4 interspace, which was consistent with herniated nucleus pulposus. Compressive myelopathy was not identified.

The patient reported nonpulsatile headache, with nausea and vomiting, immediately after myelography. Initially it appeared that he might be confused, but after repeat examination it was evident his disabilities were secondary to a disturbance of language function. Throughout this time, he maintained excellent comprehension and followed commands correctly. At first he produced, with effort and requiring considerable prompting, simple but meaningful dysarthric words spontaneously. His reading comprehension was normal. He was unable to repeat any statements presented to him, although he indicated intact auditory comprehension by head nodding. He also evidenced frustration at his inability to repeat. After several hours, his speech gradually became fluent, and there were frequent paraphasic errors. Excellent comprehension and poor repetition persisted, as did his ability to read silently. His writing ability was not tested. He remained oriented but uncomfortable, as the headache, nausea, and vomiting continued throughout this period. However, he did not appear at anytime to be clinically encephalopathic. 
During the postmyelography period, laboratory testing revealed normal levels of electrolytes and serum glucose. Cerebrospinal fluid obtained during myelography was clear and colorless, with a normal cell count; protein and glucose values were also normal. Cultures of this fluid for bacterial pathogens were negative. An EEG showed continous anteriorly predominating triphasic delta waves superimposed on generalized background slowing. An unenhanced computed tomography (CT) scan of the head demonstrated uptake of metrizamide diffusely over the cerebral hemispheres, including the temporal lobes and perisylvian regions.

The patient was treated with a bolus of dexamethasone (10 $\mathrm{mg}$ administered intravenously), followed by $4 \mathrm{mg}$ of the drug given intravenously every 6 hours. Although no seizures were observed, he also received phenytoin intravenously. All symptoms gradually subsided over the ensuing 48 hours, without any residual neurologic deficits (except for the pre-existing paraparesis).

At discharge from the hospital and during a follow-up visit six weeks later, he manifested no language disturbance. He was amnesic for the entire event and recalled only information provided to him by others.

\section{Discussion}

Aphasia is defined by Benson 13 as "the loss or impairment of language caused by brain damage." Many different aphasia syndromes, which reflect various areas of cortical or subcortical involvement, or both, have been described in clinical practice. Classification generally is achieved first by separation of the patient's spontaneous speech into fluent or nonfluent categories. ${ }^{14}$ Broca's aphasia, in which a reduced quantity of slow, effortful, dysarthric, and agrammatic speech is characteristic, is the most common example of nonfluent disorders. Wernicke's and conduction aphasia are the two most common fluent disturbances; speech is effortless, well articulated, and normal to increased in quantity, but is is qualitatively abnormal and often contains paraphasic word substitutions. Both of these show abnormality of repetition, but the persistence of normal auditory comprehension distinguishes conduction from Wernicke's aphasia. While these three types of aphasia usually are part of stroke syndromes, anomic aphasia, another fluent form in which both comprehension and repetition are preserved, is most characteristic of widespread metabolic or traumatic disorders.

Not infrequently, nonfluent output, even mutism, precedes the development of a characteristic type of aphasia; therefore, judgment should be reserved until a degree of stability is achieved. The best clinical fit then is employed in arriving at an opinion regarding the nature of the aphasia, with the final goal being one of anatomic localization and perhaps even etiologic diagnosis.

The following criteria are necessary for the di- agnosis of conduction aphasia: (1) fluent, paraphasic conversational speech; (2) normal comprehension; and (3) repetition disturbance of a significant degree. $^{11}$

Within two hours following metrizamide myelography, our patient developed a nonfluent aphasia without other focal deficit or evidence of generalized toxic-metabolic encephalopathy. He had enough difficulty expressing himself to appear confused. The neurologic findings were limited to disturbance of language function and the persisting paraparesis. His aphasia rapidly evolved over several hours into a fluent form that met all criteria for conduction aphasia.

The epileptogenic potential of metrizamide has been well established. ${ }^{1,2}$ The seizures observed mainly have been convulsive, but absence status epilepticus has been reported. ${ }^{6,7}$ The report of Pritchard and O'Neal ${ }^{6}$ included EEG evidence of generalized and frontally predominant triphasic delta waves, while generalized spike-wave and polyspike-wave complexes were recorded in the patient of Vollmer and associates. ${ }^{7}$ The clinical features of complex partial status epilepticus also have been reported ${ }^{15}$ after metrizamide myelography use; the EEG showed spikes and sharp waves of shifting and nonfocal character. The latter have been associated with absence status, but they can also occur in encephalopathies without clinical evidence of epilepsy. ${ }^{16}$ Therefore, the EEG findings of some epilepsy patients may, in fact, be due to encephalopathy rather than epilepsy.

Triphasic sharp waves also have been recorded ${ }^{3-5}$ in the nonepileptic metabolic encephalopathy associated with metrizamide; this disorder was characterized by confusion, asterixis, and agitation. A nonepileptic mechanism for metrizamide encephalopathy has been suggested, ${ }^{4}$ and some clinical and experimental evidence suggests that triphasic sharp waves may result from derangement of cerebral metabolism rather than the specific physiologic events of epilepsy. ${ }^{5}$ We conjecture that precipitation of encephalopathy by the metabolic effects of metrizamide is more common than the activation of hitherto unrecognized epilepsy by metrizamide administration.

Following metrizamide studies in a patient who showed abnormal regional cerebral blood flow in the left hemisphere, Masdeu and coworkers ${ }^{8}$ reported nonfluent aphasia that was not clearly characterized as Broca's aphasia or as a transcortical motor type. A pre-existing left hemisphere cortical lesion was postulated to be the cause of the aphasia. Eight of 67 patients studied by Butler and associates ${ }^{9}$ after metrizamide tomography had global or nonfluent aphasia. Two had left hemisphere 
EEG abnormalities, and one had left hemisphere metrizamide uptake on CT scanning. All eight had been placed in the left lateral decubitus position for pluridirectional tomography, while no patients who had been in the right lateral decubitus position developed aphasia. The authors suggested that left perisylvian irritation by metrizamide was responsible for the aphasia.

Our patient had CT evidence of generalized metrizamide uptake and electroencephalographic evidence of generalized cerebral dysfunction, so it appears that his aphasia occurred in conjunction with a generalized rather than a focal metrizamide effect. The hypothesis of Butler and associates ${ }^{9}$ would imply that patients placed in the right lateral decubitus position might develop nondominant hemisphere syndromes of agnosia and neglect, but this possibility was not specified in their report.

Conduction aphasia has been ascribed to interruption of the arcuate fasciculus connecting Broca's and Wernicke's areas. ${ }^{10}$ However, clinically and pathologically studied cases of conduction aphasia do not support a single anatomic substrate for this language disorder. ${ }^{11}$ Mendez and Benson ${ }^{12}$ recently described three atypical cases of conduction aphasia with temporoparietal lesions quite distinct from the previously described involvement of the arcuate fasciculus. They suggested that conduction aphasia resulted from disconnection of language comprehension from motor speech output at any point in its multile circuits. This could be produced by a variety of lesions, including general depression of brain function, as was probably the cause in our patient. This case supports the contention that conduction aphasia can arise from a variety of disturbances in the relationships between cerebral areas subserving language comprehension and speech output. The disturbances might involve multiple sites more commonly than a single lesion in the arcuate fasciculus.

Finally, it should be noted that the newer nonionic, water-soluble contrast agents iohexol and iopamidol are replacing metrizamide in myelography. ${ }^{17}$ These agents are reported to have less central nervous system toxicity and a lower incidence of adverse reactions than does metrizamide. ${ }^{18,19}$

\section{Summary}

Metrizamide can produce conduction aphasia by inducing global cerebral dysfunction. The mechanism is hypothesized to be a nonspecific interruption of perisylvian connections between speech areas. Aphasia should be added to the reports of transient neurologic complications of metrizamide myelography.
1. Junck L, Marshall WH: Neurotoxicity of radiological contrast agents. Ann Neurol 1983;13:469-484.

2. Killebrew K, Whaley RA, Hayward JN, et al: Complications of metrizamide myelography. Arch Neurol 1983;40:78-80.

3. Vincent FM, Zimmerman JE: Metrizamide encephalopathy. Ann Neurol 1980;7:484-489.

4. Bertoni JM, Schwartzman RJ, Van Horn G, et al: Asterixis and encephalopathy following metrizamide myelography: Investigations into possible mechanisms and review of the literature. Ann Neurol 1981;9:366370 .

5. Drake ME, Erwin CW: Triphasic EEG discharges in metrizamide encephalopathy. $J$ Neurol Neurosurg Psychiatry 1984;43:324-325.

6. Pritchard PB III, O'Neal DB: Nonconvulsive status epilepticus following metrizamide myelography. Ann Neurol 1984;16:252-254.

7. Vollmer ME, Weiss H, Beanland C, et al: Prolonged confusion due to absence status following metrizamide myelography. Arch Neurol 1985;42:1005-1008.

8. Masdeu JC, Glista GG, Rubino FA, et al: Transient motor aphasia following metrizamide myelography. AJNR 1983;4:200-202.

9. Butler MJ, Cornell SH, Damasio AR: Aphasia following pluridirectional tomography with metrizamide: The effect of patient position. Arch Neurol 1985;42:39-45.

10. Wernicke C: Der Aphasische Symptomenkomplex. Breslau, Cohen, und Weigert, 1874.

11. Benson DF, Sheremata WA, Bouchard R, et al: Conduction aphasia: A clinicopathologic study. Arch Neurol 1973;28:339-346.

12. Mendez MF, Benson DF: Atypical conduction aphasia. A disconnection syndrome. Arch Neurol 1986;42:886-893.

13. Benson DF: Aphasia, alexia, and agraphia. New York, Churchill Livingstone, Inc., 1979.

14. Geschwind N: Aphasia. N Engl J Med 1971;284:654-656.

15. Russell D, Anke IM, Nyberg-Hansen R, et al: Complex partial status epilepticus following metrizamide myelography. Ann Neurol 1980;8:325327.

16. Fincham RW, Yamada T, Schottelius DD, et al: Electroencephalographic absence status with minimal behavior change. Arch Neurol 1979;36:176-178.

17. Lamb JT: Iohexol vs. iopamidol for myelography. Invest Radiol January-February 1985;20(suppl 1):537-543.

18. Kieffer SA, Binet EF, Davis DO, et al: Lumbar myelography with iohexol and metrizamide: A comparative multicenter prospective study Radiology 1984;151:665-670.

19. Gonsette RE, Liesenborghs L: Iohexol: A new nonionic contrast medium for myelography and cisternography with markedly reduced neurotoxicity. Invest Radio January-February 1985;20(suppl):537-543.

From the Department of Neurology, Ohio State University, Columbus Ohio. Dr. Kassicieh is now in private practice of neurology in Sarasota, Fla.

Reprints requests to Dr Kassicieh, No 207, 800 Hudson Ave, Sarasota, FL 34236. 


\section{Rapid,unsurpassed relief}

that lets patients stay alert so they

\section{can perform at their best}
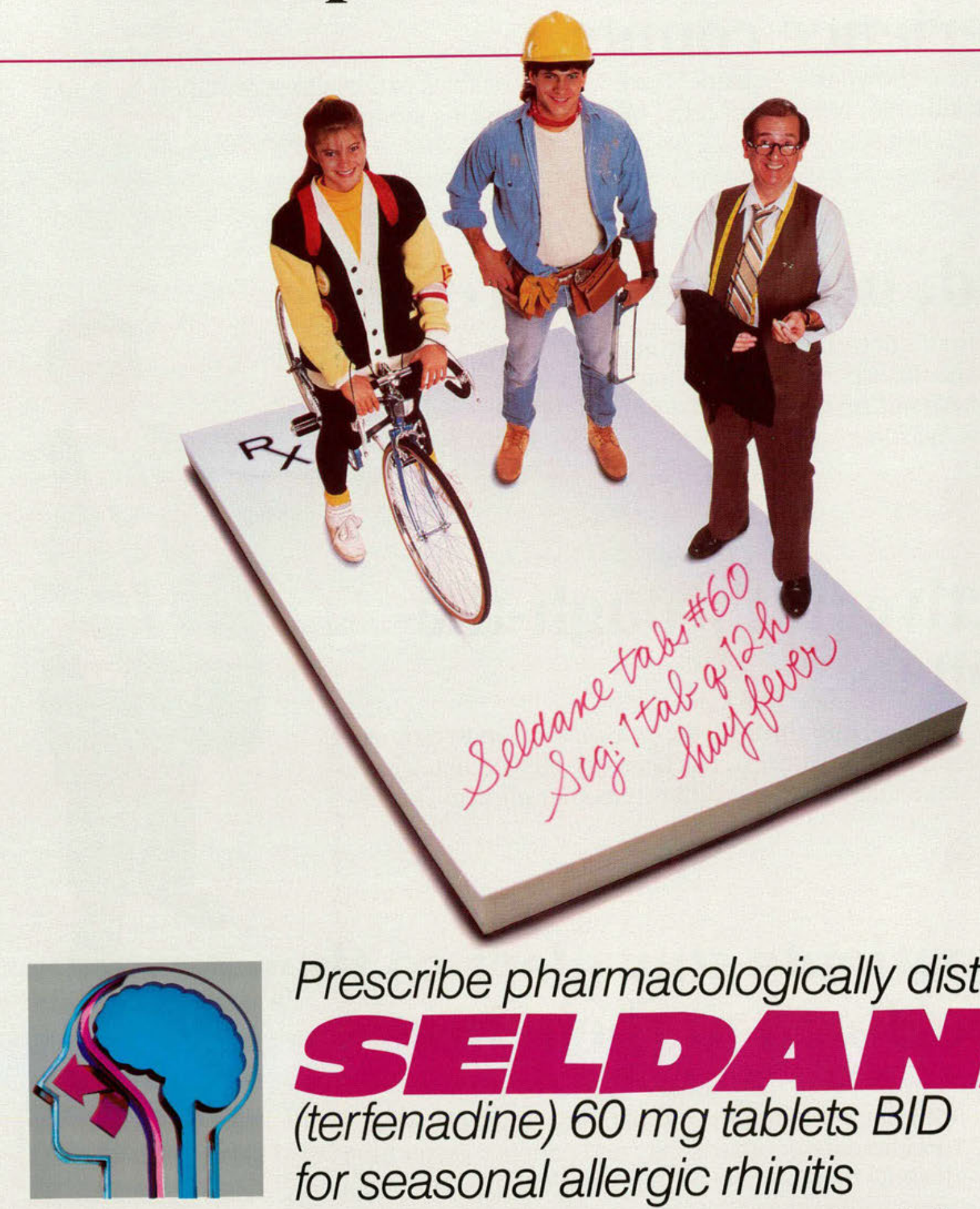

Prescribe pharmacologically distinct

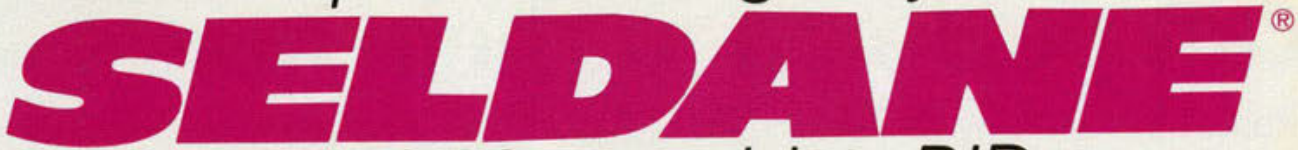

(terfenadine) $60 \mathrm{mg}$ tablets BID

for seasonal allergic rhinitis

The ideal profile for fast, on-the-job relief 


\section{The \#1 prescribed allergy product in the U.S.*... now with more than 30 million patient-months of experience worldwide}

\section{Experience counts. And both extensive evaluation and extensive experience have shown that Seldane (terfenadine) enables patients to stay at their best and also get fast, reliable, convenient relief of allergic rhinitis symptoms.}

\section{PRONEN}

\section{Rapid, unsurpassed relief}

22 double-blind, controlled clinical studies, involving 3,049 patients, have

proven Seldane unsurpassed in relieving seasonal allergic rhinitis symptoms. ${ }^{1-4}$ No antihistamine - past or present-has been proven more effective than Seldane.

\section{PRONIEN}

\section{Effective in through-the-}

\section{season use}

The efficacy of Seldane in through-the-season use (up to 6 months), without development of tolerance, has been established in a widespread U.S. multicenter study, ${ }^{3}$ and in three other clinical studies. ${ }^{5-7}$

\section{PRONEN}

\section{Lets patients stay alert so they can perform at their best}

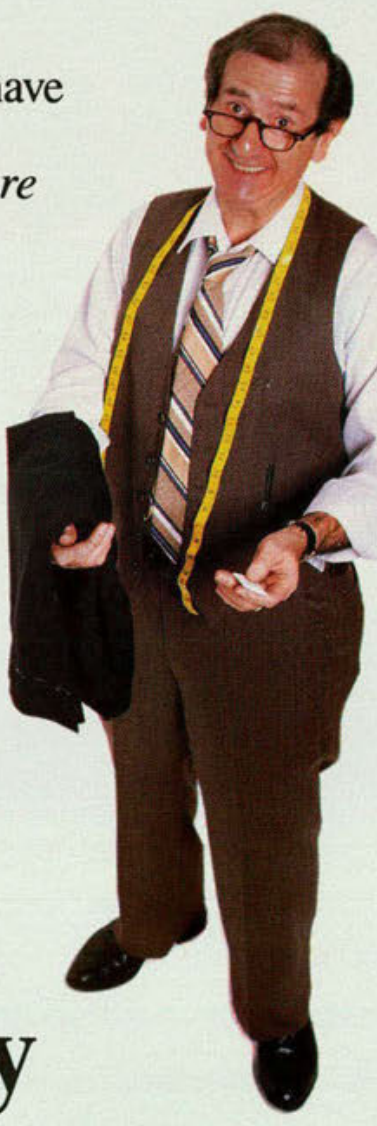

Studies using many different techniques-including controlled clinical trials involving more than 1,700 patients, ${ }^{3}$ multiple sleep latency tests, ${ }^{8}$ EEG activity comparisons, ${ }^{9}$ and patients' own ratings of alertness-all show that Seldane is comparable to placebo in EEG activity, drowsiness, ${ }^{*}$ and other CNS effects. (See Prescribing Information for Contraindications, Precautions, and Adverse Reactions.) 

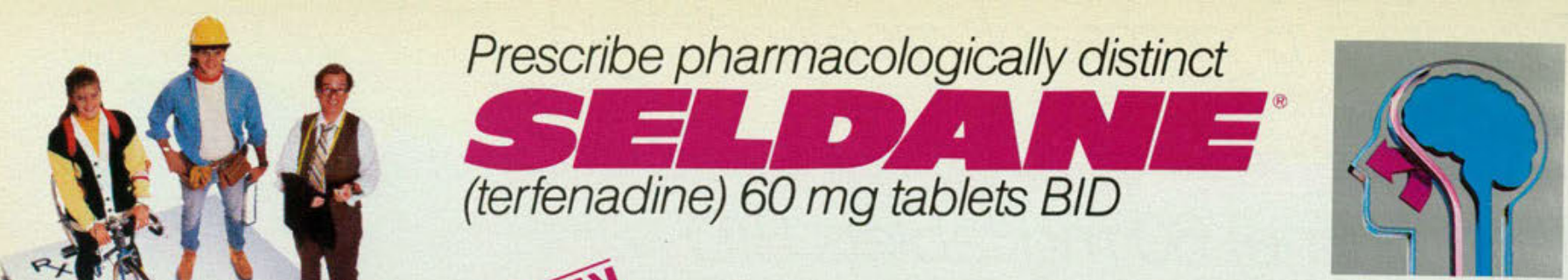

DIRONIEN

\section{Rapid, unsurpassed relief that lets patients stay alert so they can perform at their best}

\section{Seldane ${ }^{\circledR}$ (terfenadine)}

$60 \mathrm{mg}$ Tablets

CAUTION: Federal law prohibits dispensing without prescription.

DESCRIPTION

Seldane (terfenadine) is available as tablets for oral administration. Each tablet contains $60 \mathrm{mg}$ tertenadine. Tablets also contain, as inactive ingredients: corn starch, gelatin, lactose, magnesium stearate, and sodium bicarbonate. Terfenadine is a histamine $H_{1}$-receptor antagonist with the chemical name $\alpha$-[4-(1,1-Dimethylethyl) phenyl) -4-(hydroxydiphenylmethyl)-1-piperidinebutanol.

It has the following

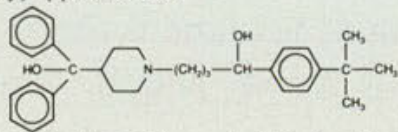

Terfenadine occurs as a white to off-white crystalline powder. It is freely soluble in chloroform, soluble in ethanol and very slightly soluble in water.

CLINICAL PHARMACOLOGY

Terfenadine is chemically and pharmacologically distinct from other antihistamines.

Histamine skin wheal studies have shown that Seldane in single and repeated doses of $60 \mathrm{mg}$ in 64 subjects has an antihistaminic effect beginning at $1-2$ hours, reaching its maximum at $3-4$ hours, and lasting in excess of 12 hours.

Clinical trials of Seldane involved about 2.600 patients, most receiving either Seldane, another antihistamine and/or placebo in double-blind, randomized controlled comparisons. The four best controlled and largest trials each lasted days and involved about 1,000 total patients in comparisons of Seldane $(60 \mathrm{mg}$ b.i.d.) with an active drug (chlor $50-70 \%$ of Seldane or other antihistamine recipients had moderate to compline $1 \mathrm{mg}$ b.i.d.). In the four trials, about $30-50 \%$ of placebo recipients. with a significant difference tavoring the active drugs in each study, in these studies, Seldane was associated with less frequent drowsiness than the other antihistamines; the frequency of drowsiness with Seldane was similar to the frequency with placebo. None of these studies showed a difference between Seldane and other antihistamines in the frequency of anticholinergic effects. In studies which included 52 subjects in whom EEG assessments were made, no depressant effects have been observed.

Animal studies have demonstrated that terfenadine is a peripheral specific histamine $\mathrm{H}_{1}$-receptor antagonist. In these animal studies, no sedative or anticholinergic effects were observed at effective antihistaminic doses. $H_{1}$-receptors indicate that, at effective antihistamine doses, neither tertenadine nor its metabolites penetrate the blood brain barrier well.

Pharmacokinetic studies in 27 male subjects, using 14C-labeled terfenadine, demonstrated that an oral dose of terfenadine is well absorbed from the gastrointestinal tract and rapidly and extensively biotransformed. Following administration of a single $60 \mathrm{mg}$ Seldane tablet, detectable plasma levels were observed within one-half hour. Plasma levels peaked at about 2 hours after administration; a distribution half-life of 3.4 hours was followed by an elimination haff-life of 20.25 hours. Terfenadine is extensively $(97 \%)$ bound to human serum protein. Elimination studies in 6 male volunteers showed that fecal excretion accounted for $60 \%$ of the dose while $40 \%$ of the dose was eliminated via the urine. Almost all of the dose was eliminated in the form of metabolic products.

Following administration of single doses of 60 or $180 \mathrm{mg}$ of Seldane, a linear response was observed in maximum plasma concentration. Area under the curve (AUC) calculations, however, indicate a nearly four-fold increase in response for a three-fold increase in dose.

INDICATIONS AND USAGE

Seldane is indicated for the relief of symptoms associated with seasonal allergic rhinitis such as sneezing. CONTRAINDICATIONS

Seldane is contraindicated in patients with a known hypersensitivity to terfenadine or any of its ingredients.

PRECAUTIONS

Information for patients

Patients taking Seldane should receive the following information and instructions. Antihistamines are prescribed to reduce allergic symptoms. Patients should be questioned about pregnancy or lactation before starting Seldan risk to fetus or baby. Patients should be instructed to take Seldane only as needed and not to exceed the prescribed isk to etus or baby. Patients should be instructed to take Seldane only as needed and not to exceed the prescribed away from heat or direct sunlight, and away from children.

Carcinogenesis, mutagenesis, impairment of fertility

Oral doses of terfenadine, corresponding to 63 times the recommended human daily dose, in mice for 18 months or in rats for 24 months, revealed no evidence of tum

Reproduction and fertility studies in rats showed no effects on male or female fertility at oral doses of up to 21 times the human daily dose. At 63 times the human daily dose there was a small but significant reduction in implants an were judged to be secondary to maternal toxicity.

Pregnancy Category C

There was no evidence of animal teratogenicity. Reproduction studies have been performed in rats at doses 63 times and 125 times the human daily dose and have revealed decreased pup weight gain and survival when studies in pregnant women. Seldane shourd be used during pregnancy only it the potential benefit iustifies the potential risk to the fetus.

Nonteratogenic effects

Seldane is not recommended for nursing women. The drug has caused decreased pup weight gain and survival in rats given doses 63 times and 125 times the human daily dose throughout pregnancy and lactation. Effects on pups exposed to Seldane only during lactation are not known, and there are no adequate and well-controlled studies women during lactation.

Pediatric use

Pety and effectiveness of Seldane in children below the age of 12 years have not been established.

General

Consideration should be given to potential anticholinergic (drying) effects in patients with lower airway disea isthma.

\section{ADVERSE REACTIONS}

Experience from clinical studies, including both controlled and uncontrolled studies involving more than 2,4 pants wix was as low as $20 \mathrm{mg}$ twice a day, or as high as $600 \mathrm{mg}$ daily.

In controlled clinical studies using the recommended dose of $60 \mathrm{mg} \mathrm{b.i.d.,} \mathrm{the} \mathrm{incidence} \mathrm{of} \mathrm{reported} \mathrm{adver}$ effects in patients receiving Seldane was similar to that reported in patients receiving placebo. (See Table belo ADVERSE EVENTS REPORTED IN CLINICAL TRIALS

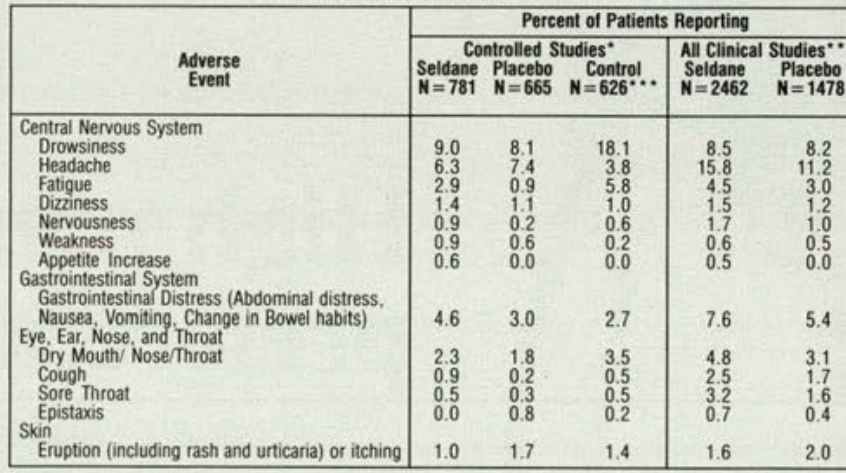

-Duration of treatment in "CONTROLLED STUDIES" was usually 7-14 DAYS.

"Duration of treatment in "ALL CLINICAL STUDIES" was up to 6 months.

-..CONTROL DRUGS: Chlorpheniramine (291 patients), d-Chlorpheniramine (189 patients), Clemastine (146 patien In addition to the more frequent side effects reported in clinical trials (See Table), adverse effects have be reported at a lower incidence in clinical trials and/or spontaneously during marketing of Seldane that warrant listi as possibly associated with drug administration. These include: alopecia, anaphylaxis, angioedema, arriyth nia. menstrual disorders (including dysmenorrthea), musculoskeletal symotoms, nightmares, palpitation, esthesia, photosensitivity, sweating syncope, tachycardia, tremor, urinary frequency, and visual disturbances clinical trials several instances of mild, or in one case, moderate transaminase elevations were seen in patien receiving Seidane. Mild elevations were also seen in placebo treated patients. Marketing experiences inclu isolated reports of jaundice, cholestatic hepatitis, and hepatitis; in most cases available information is incomple In neither the clinical trials nor marketing experience is a causal relationship of liver abnormalities to Seldane clear.

OVERDOSAGE

Several cases of overdosage have been reported. Generally, signs and symptoms were absent or mild (e. headache, nausea, confusion). However, a severe ventricular arrhythmia (torsade de pointes) developed 15 hou after ingestion of 56 tablets $(3360 \mathrm{mg}$ ) of Seldane, 14 capsules $(7000 \mathrm{mg})$ of cephalexin, and 2 tablets (1200 mg ibuprofen. This progressed to ventricular fibrillation which responded well to defibrillation and lidocaine.

Therefore, in cases of overdosage, cardiac monitoring for at least 24 hours is recommended, along with stand measures to remove any unabsorbed drug. It is not known if Seldane is dialyzable.

Treatment of the signs and symptoms of overdosage should be symptomatic and supportive after the acute stag Oral LD 50 values for terfenadine were greater than $5000 \mathrm{mg} / \mathrm{kg}$ in mature mice and rats. The oral LD50 was 4 $\mathrm{mg} / \mathrm{kg}$ in newborn rats. Single doses as high as ten times $(600 \mathrm{mg})$ the recommended therapeutic dose in adu

DOSAGE AND ADMINISTRATIOH

The usual dosage for adults and children 12 years and older is $60 \mathrm{mg}$ (1 tablet) twice daily.

HOW SUPPLIED

$60 \mathrm{mg}$ tablets in bottles of 100 . Tablets are round, white, and debossed "SELDANE". Store tablets

controlled room temperature $\left(59^{\circ}-86^{\circ} \mathrm{F}\right)\left(15^{\circ}-30^{\circ} \mathrm{C}\right)$. Protect from exposure to temperatures above 10 $\left(40^{\circ} \mathrm{C}\right)$ and moisture.

Product Information as of August, 1987

MERRELL DOW PHARMACEUTICALS INC

Subsidiary of The Dow Chemical Company

Merrell Dow

\section{References:}

1. Kemp JP. Buckley CE. Gershwin ME, et al: Multicenter, double-blind, placebo-controlled trial of terfenadine in seasonal allergic rhinitis and conjunctivitis. Ann Allergy 54:502-509, 1985, 2. Backhouse CI, Brewster BS. Lockhart JDF, et al: Terfenadine in al lergic rhinitis. A comparative trial of a new antihistamine versus chlorpheniramine and placebo. Practitioner 226:347-348, 351, 1982, 3. Data available upon request. MERRELL DOW PHARMACEUTICALS INC., Cincinnati, Ohio 45215. 4. Melillo G. D'Amato G. Zanussi C. et al: A multicentre controlled trial of terfenadine, dexchlorpheniramine, and placebo in allergic rhinitis. Arzneim-Forsch/Drug Research 32:1202-1203, 1982. 5. Gastpar H: Long-term prevention and tolerability of Teldane (terfenadine) in allergic rhinitis. Swiss Med 4(5):47, 1982. 6. Gastpar H. Dieterich HA: Comparative study of the efficacy and tolerance of terfenadine and clemastine in patients with seasonal allergic rhinitis. Arzneim-Forsch/Drug Res 32:1211-1213, 1982. 7. Krause LB, Shuster S: The effect of terfenadine on dermographic whealing. Br J Dermatol 10:73-79, 1984. 8. Roehrs TA. Tietz EI, Zorick FJ, et al: Daytime sleepiness and antihistamines. Sleep 7(2):137-141, 1984. 9. Fink M, Irwin P CNS effects of the antihistamines diphenhydramine and terfenadine (RMI 9918). Pharmakopsychiat 12:35-44, 1979. 